\title{
Do Spanish-English bilinguals have their fingers in two pies - or is it their toes? An electrophysiological investigation of semantic access in bilinguals
}

\author{
Noriko Hoshino $^{1 *}$ and Guillaume Thierry ${ }^{2}$ \\ Department of English, Kobe City University of Foreign Studies, Kobe, Japan \\ 2 School of Psychology, Economic and Social Research Council Centre for Research on Bilingualism in Theory and Practice, Bangor University, Bangor, UK
}

Edited by:

Teresa Bajo, Universidad de Granada, Spain

\section{Reviewed by:}

Natasha Tokowicz, University of Pittsburgh, USA

Pedro Macizo, University of Granada, Spain

Patricia E. Román, Max Planck

Society, Germany

*Correspondence:

Noriko Hoshino, Department of English, Kobe City University of Foreign Studies, 9-1 Gakuen Higashi-machi, Nishi-ku, Kobe, Hyogo-ken 651-2187, Japan. e-mail: noriko.hoshino@inst. kobe-cufs.ac.jp
We examined the time course of cross-language activation during word recognition in the context of semantic priming with interlingual homographs. Spanish-English bilinguals were presented pairs of English words visually one word at a time and judged whether the two words were related in meaning while recording event-related potentials. Interlingual homographs (e.g., "pie": "Pie" in Spanish is a foot.) appeared in the target position and were preceded by primes that were either related to the English meaning (e.g., "apple"), related to the Spanish meaning of interlingual homographs (e.g., "toe") or totally unrelated (e.g., "floor"/"bed"). Spanish-English bilinguals showed semantic priming not only when interlingual homographs were related to the English meaning but also to the Spanish meaning of the prime. These priming effects were detectable in the mean amplitude of the N400 (350$500 \mathrm{~ms}$ ) even when the target word was related to the prime in Spanish and the context of the experiment was English. However, the relatedness effect was found in the window of a late positive component (LPC; $550-700 \mathrm{~ms}$ ) only for stimulus pairs related in English. To verify that the observed pattern of the results was due to participants' bilingualism, we also tested a group of English monolinguals. The monolinguals showed a semantic priming effect for the N400 and LPC time windows only when interlingual homographs were related to the English meaning. These results suggest that both languages are activated in the classical time frame of semantic activation indexed by N400 modulations, but that semantic activation in the non-target language failed to be explicitly processed.

Keywords: interlingual homographs, semantic priming, ERPs

\section{INTRODUCTION}

Previous research suggests that even when bilinguals read in one language (the target language), the other language (the non-target language) is also active and influences the process of reading in the target language to some extent (e.g., Dijkstra et al., 1999; Jared and Kroll, 2001). Some evidence for non-selective language activation comes from studies with interlingual homographs. Interlingual homographs are words whose spellings are similar but whose meanings are different across two languages (e.g., "pie" in English is food and "pie" in Spanish is a foot). Past studies have shown that the meaning of interlingual homographs in a non-target language is also activated (e.g., Beauvillain and Grainger, 1987; Dijkstra et al., 1998, 1999; Elston-Güttler, 2000; De Bruijn et al., 2001; Lemhöfer and Dijkstra, 2004; Kerkhofs et al., 2006; Paulmann et al., 2006; Macizo et al., 2010; Martín et al., 2010). However, cognitive control mechanisms effectively allow the meaning in a target language to be selected at some point in processing.

In a seminal study with interlingual homographs by Dijkstra et al. (1998), Dutch-English bilinguals performed a lexical decision task. Dijkstra and his colleagues found that Dutch-English bilinguals were slower responding to interlingual homographs (e.g., "boom" in English is a sudden increase and "boom" in Dutch is a tree) than to English control words (e.g., "riot") when some Dutch words were included in the task. This inhibitory effect was also modulated by the relative frequency of interlingual homograph meaning across languages. A greater inhibition was observed when the frequency of the meaning of the homograph in Dutch was high than when it was low. These results suggest that not only the reading of interlingual homographs in one language but also its reading in the other language is active and participates in the competition for selection.

If the meaning of interlingual homographs in a non-target language is also activated, how do bilinguals select the meaning of words presented in a target language? Using a negative priming paradigm, Macizo et al. (2010) have recently shown that the non-target meaning of interlingual homographs is activated but inhibited subsequently. In their study, Spanish-English bilinguals made semantic judgments on pairs of English words. The bilinguals responded more slowly to pairs involving homographs (e.g., pie-toe; "pie" meaning "foot" in Spanish) than to pairs without homographs. Critically, participants were slower when the pair included the translation of the Spanish meaning of the homograph (e.g., foot-hand) after a trial involving an homograph (e.g., pietoe), but not after a trial involving a control word (e.g., $\log$-toe). 
These results suggest that the Spanish (non-target) meaning of homographs is activated initially and inhibited subsequently. Furthermore, Martín et al. (2010) found this inhibitory effect when the subsequent trial was initiated $500 \mathrm{~ms}$ after responding to pairs involving homographs, but not $750 \mathrm{~ms}$. This finding suggests that the reactive inhibition decays over time.

However, it remains undetermined when the activation of the non-target language is present. In the study by Macizo et al. (2010) and Martín et al. (2010), the inhibition of the non-target meaning was assessed during the presentation of a subsequent pair but online temporal monitoring of inhibition processes was not available. In the present study, we investigated the time window in which the non-target language is accessed in late Spanish-English bilinguals reading English. We used a classical semantic priming paradigm and we recorded event-related potential (ERPs). The study of Kerkhofs et al.'s (2006) investigating semantic priming with interlingual homographs in Dutch-English bilinguals is directly relevant here. Kerkhofs et al. (2006) showed that the primes that were semantically related to the English meaning of homographs facilitated the recognition of English homograph targets as indexed by N400 modulations. The N400 is thought to reflect lexical-semantic processing (e.g., Kutas and Hillyard, 1980 for semantics; Thierry and Wu, 2007 for form). Critically, Kerkhofs et al. (2006) found that the mean amplitude of the N400 was also modulated by the frequency of the non-target Dutch meaning of homographs, suggesting that the non-target representations of interlingual homographs also affect N400 modulation. Here, unlike Kerkhofs et al. (2006), we included primes that were semantically related to the non-target meaning of homographs as well as primes that were semantically related to the target meaning of homographs to assess the degree of non-target language activation, instead of manipulating the relative frequency of homograph meanings.

We asked Spanish-English bilinguals and English monolinguals to perform a semantic relatedness task on words presented in pairs within a go/no-go paradigm in which all the critical trials belonged to the no-go condition to prevent contamination of the ERPs by response-specific decision processes (e.g., Midgley et al., 2009; Thierry et al., 2009; Hoshino et al., 2010). This designed enabled us to compare the level of priming found for words related in L1 and words related in the non-target L2 indexed by N400 modulations. Furthermore, we examined the modulation of a late positive component (LPC), associated with explicit/controlled processing and stimulus re-evaluation (e.g., Thierry et al., 1998, 2003; Martin et al., 2009, 2010). If the non-target meaning of interlingual homographs continues to be active and/or is explicitly processed at a post-lexical processing stage, we should observe an LPC modulation in the non-target language as well as an N400 modulation. Specifically, we predicted that bilingual participants would access their first language (L1) during second language (L2) word reading whilst monolingual English participants would show no homograph priming effect (since they did not know Spanish). We were interested in measuring the magnitude of semantic priming in the window of the N400 and assessing the explicit or implicit nature of $\mathrm{L} 1$ activation. We expected priming to be weaker and more short-lived in the L1 Spanish than the L2 English, given that the L1 Spanish was not the target language. Therefore, we predicted that semantic priming in the non-target language Spanish would be measurable in the window of the N400, but might not result in modulation in the LPC range.

\section{MATERIALS AND METHODS PARTICIPANTS}

Fourteen Spanish-English bilinguals and 14 English monolinguals participated in the study. All of the Spanish-English bilinguals spoke English as an L2 and were dominant in their L1. The characteristics of the two groups are provided in Table 1. Participant gave informed consent to take part in the study, which was approved by the ethics committee of Bangor University, Wales.

\section{MATERIALS}

\section{Semantic judgment task}

The critical stimuli consisted of 72 interlingual homographs (e.g., pie) and two sets of 72 non-cognates (e.g., apple). The mean length of the homographs was 5.1 letters $(\mathrm{SD}=1.7)$ and the mean lexical frequency was $75.3(\mathrm{SD}=144.4)$ based on the CELEX database (Baayen et al., 1995). The two sets of non-cognates were matched on length $[M=5.4, \mathrm{SD}=1.7 ; M=5.5, \mathrm{SD}=1.7 ; t(72)=-0.73$, $p>0.10]$ and lexical frequency $[M=121.3, \mathrm{SD}=227.5 ; M=76.5$, $\mathrm{SD}=108.4 ; t(72)=1.61, p>0.10]$. Four types of word pairs were formed where the first word was a non-cognate prime and the second word an interlingual homograph target. Primes and targets were either related (e.g., apple-pie) or unrelated (e.g., rug-pie) in English, and either related (e.g., toe-pie) or unrelated (e.g., stove-pie) when considering the target's meaning in Spanish. The Edinburgh Associative Norms were used to generate prime words. Because each target followed a prime in the semantic judgment task, the target was entered as a response, not as a stimulus in the Norms. The associative strength of related pairs for the English reading was 0.14 , whereas that of related pairs for the Spanish

Table 1 | Characteristics of English monolinguals and Spanish-English bilinguals.

\begin{tabular}{llc}
\hline Measure & $\begin{array}{l}\text { Monolinguals } \\
(\boldsymbol{n}=\mathbf{1 4})\end{array}$ & $\begin{array}{c}\text { Bilinguals } \\
(\boldsymbol{n}=\mathbf{1 4})\end{array}$ \\
\hline Age (years) & $21.3(5.4)$ & $27.0(5.5)$ \\
L1 self-rating (10 pt scale) & $9.3(0.8)$ & $9.7(0.5)$ \\
Reading & $9.3(0.9)$ & $9.6(0.6)$ \\
Writing & $9.0(1.1)$ & $9.4(0.9)$ \\
Speaking & $9.3(0.9)$ & $9.8(0.4)$ \\
Listening & $9.4(0.8)$ & $9.9(0.3)^{*}$ \\
L2 self-rating (10 pt scale) & N/A & $7.1(1.7)$ \\
Reading & N/A & $7.6(1.5)$ \\
Writing & N/A & $7.1(1.9)$ \\
Speaking & N/A & $6.8(2.0)$ \\
Listening & N/A & $7.1(1.6)$ \\
Daily L1 usage (\%) & N/A & $44.3(26.2)$ \\
Daily L2 usage (\%) & N/A & $55.7(26.2)$ \\
Age of L2 acquisition (years) & N/A & $9.7(4.4)$ \\
Length of immersion (months) & N/A & $43.7(62.8)$ \\
\hline
\end{tabular}

SDs are in parentheses. ${ }^{*} p<0.05$. 
reading was $0.22(p>0.10)$. Therefore, if anything, the associative strength was greater for the Spanish reading. One set of non-cognates was used for related and unrelated primes in English and the other set for related and unrelated primes in Spanish. That is, the list of critical stimuli consisted of 72 English related trials, 72 English unrelated trials, 72 Spanish related trials, and 72 Spanish unrelated trials. It is important to note that the primes for English related were identical to those for English unrelated but appeared in the context of a different target (e.g., rug-carpet, rug-pie). Likewise, the other set of 72 non-cognates comprised the primes for Spanish related and unrelated. This design allowed us to minimize the possibility that observed differences in ERPs across conditions would be due to differences in terms of stimulus physical features or lexical properties rather than to the relationship between prime and target. Note that we used the same number of related and unrelated trials to avoid spurious P3/P600 contamination due to imbalanced probability between experimental conditions. If we had used only one set of unrelated pairs for two sets of related ones, we may have elicited P3/P600 effects just by virtue of their relatively lower probability (33\% instead of 50\%).

In addition to the critical stimuli, 216 non-cognates were selected to generate filler pairs: 144 non-cognates (two sets of 72 non-cognates) as primes and 72 as targets. Similar to the construction of the critical stimuli, each target word was paired with four different primes - two of them related and the other two unrelated. None of the filler items were the same as the experimental words. A total of 288 filler pairs were created. Half of the filler pairs served as probes as in a go/no-go semantic verification task in which participants were asked to press a yes/no button when the target was presented in red. Each filler target was presented twice in red and twice in black. Therefore, in the present study, all the critical pairs belonged to no-go trials.

Participants completed four blocks of 72 critical trials ( 18 trials per condition in each block) and 72 filler trials (18 go trials with yes responses, 18 go trials with no responses, and 36 no-go trials). Thus, the total number of critical trials was 288 trials (72 per condition). Each target and prime appeared only once in each block. The order of blocks was counterbalanced across participants and the presentation of items was randomized within each block.

\section{Language history questionnaire}

A questionnaire was designed to obtain information about participants' language learning experiences (see Tokowicz et al., 2004, for a similar instrument).

\section{PROCEDURE}

Participants were given the semantic judgment task, followed by the language history questionnaire.

\section{Semantic judgment task}

Participants were informed that a series of English word pairs would be presented and their task would be to judge whether the two words were related in meaning. They were asked to press a left button if the second word of a pair was red and related to the previous word and to press a right button if the word was red and unrelated. If the second word of a pair was black, they were asked not to press any button. On each trial, a prime word was presented for $300 \mathrm{~ms}$, followed by a $300 \mathrm{~ms}$ interstimulus interval and then a target word. The target word remained on the screen for $1500 \mathrm{~ms}$ or until the participants pressed a button. At the end of the trial, the screen remained blank for $700 \mathrm{~ms}$. Twelve practice trials preceded the experimental trials.

\section{ELECTROPHYSIOLOGICAL RECORDING}

The EEG was continuously recorded at a rate of $1 \mathrm{kHz}$ from 64 $\mathrm{Ag} / \mathrm{AgCl}$ electrodes placed according to the extended 10-20 convention. The 64 electrodes were referenced to $\mathrm{Cz}$ online. Eye blinks were monitored through additional electrodes attached above and below the right eye. Impedances were maintained below $5 \mathrm{k} \Omega$. EEG signals were filtered online with a bandpass of $0.01-200 \mathrm{~Hz}$ and re-filtered off-line with a $30 \mathrm{~Hz}$ low pass zero phase shift digital filter.

\section{DATA ANALYSES}

Eye-blink artifacts were mathematically corrected using the algorithm provided in Scan 4.4 (Neuroscan, Inc.). Trials with uncorrected eye-blink artifacts and other artifacts such as horizontal eye movements and muscle movements were manually dismissed. The number of accepted trials was on average 66 per experimental condition and did not differ significantly between experimental conditions $(p>0.10)$. ERPs were then computed by averaging EEG epochs from -100 to $800 \mathrm{~ms}$ after the onset of the stimulus. Baseline correction was applied in relation to $100 \mathrm{~ms}$ of pre-stimulus activity and individual averages were re-referenced to the average of the left and right mastoid electrodes. ERPs time-locked to the target word were visually inspected and two expected ERP components (N400 and LPC) were identified. They were both maximal over centroparietal electrodes as predicted by the literature (e.g., Kutas and Hillyard, 1980; Martin et al., 2009, 2012). Peak latencies were measured at sites of maximal amplitude and mean ERP amplitudes were measured in a region of interest around the site of maximal amplitude taking into account mean global field power variations (Picton et al., 2000; Luck, 2005; centroparietal region: $\mathrm{C} 1, \mathrm{C} 2, \mathrm{Cz}, \mathrm{CP} 1, \mathrm{CP} 2, \mathrm{CPz}, \mathrm{P} 1, \mathrm{P} 2$, and $\mathrm{Pz}$ ). The time window for each component was defined a priori based on previous research: 350-500 ms for the N400 (e.g., Kuipers and Thierry, 2010; Hoshino and Thierry, 2011) and 500-650 ms for the LPC (e.g., Martin et al., 2009, 2010). For statistical analyses, a four-way ANOVA was performed on mean amplitudes for each component with relatedness (related and unrelated), homograph language status (Spanish and English meaning), and electrode site (C1, C2, Cz, CP1, CP2, $\mathrm{CPz}, \mathrm{P} 1, \mathrm{P} 2$, and $\mathrm{Pz}$ ) as within-participants variables and language group (bilinguals and monolinguals) as a between-participants variable. The Greenhouse-Geisser correction was applied to variables with more than one degree of freedom in the numerator (Greenhouse and Geisser, 1959). Reported degrees of freedom are uncorrected but $p$-values are corrected. Significant interactions were further examined with simple effects tests. We do not report main effects of electrode site and report interactions between electrode site and other independent variables only when they are significant.

\section{RESULTS}

Event-related potentials displayed a classical P1-N1-P2 pattern in all conditions and in both participant groups. The P1, N1, and P2 
did not differ in amplitude or latency between groups and conditions. An N2 modulation was visible just before the N400 time

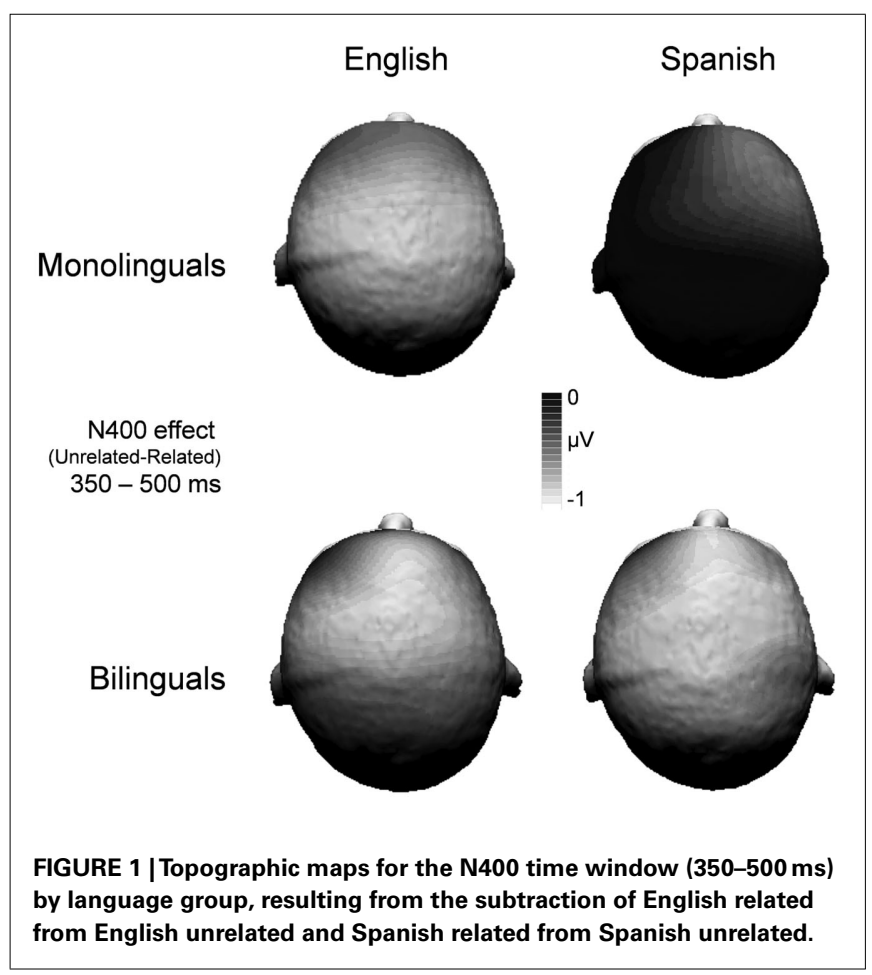

window. There was no main effect of homographs language status, relatedness, or group on the amplitude of the N2. There was a marginal interaction between all three factors $[F(1,26)=3.68$, $p=0.07]$. There was no effect of any factor or interaction on $\mathrm{N} 2$ peak latencies and this was also the case for N400 and LPC.

\section{N400 (350-500 ms)}

The N400 was maximal over the centroparietal region (see Figure 1). There were significant main effects of relatedness and homograph language status on N400 mean amplitude $[F(1$, $26)=33.79, p<0.001 ; F(1,26)=4.94, p<0.05$, respectively]. The main effect of language group did not emerge $(F<1)$. The interactions between relation and homograph language status and between homograph language status and language group were significant $[F(1,26)=15.48, p<0.01 ; F(1,26)=4.64, p<0.05$, respectively]. There was no interaction between relatedness and language group $(F<1)$. Most critically, the three-way interaction of relatedness, homograph language status, and language group was significant $[F(1,26)=9.77, p<0.01]$.

To further investigate the three-way interaction, simple effects tests were performed. As can be seen in Figure 2, monolinguals showed the interaction between relatedness and homograph language status $[F(1,13)=26.74, p<0.001]$, whereas bilinguals did not $(F<1)$. Specifically, monolinguals showed that the mean amplitude of the related condition was significantly reduced, relative to the mean amplitude of the unrelated condition for the English homograph meaning $[F(1,13)=39.27, p<0.001]$, but not for the Spanish homograph meaning $(F<1)$. In contrast,
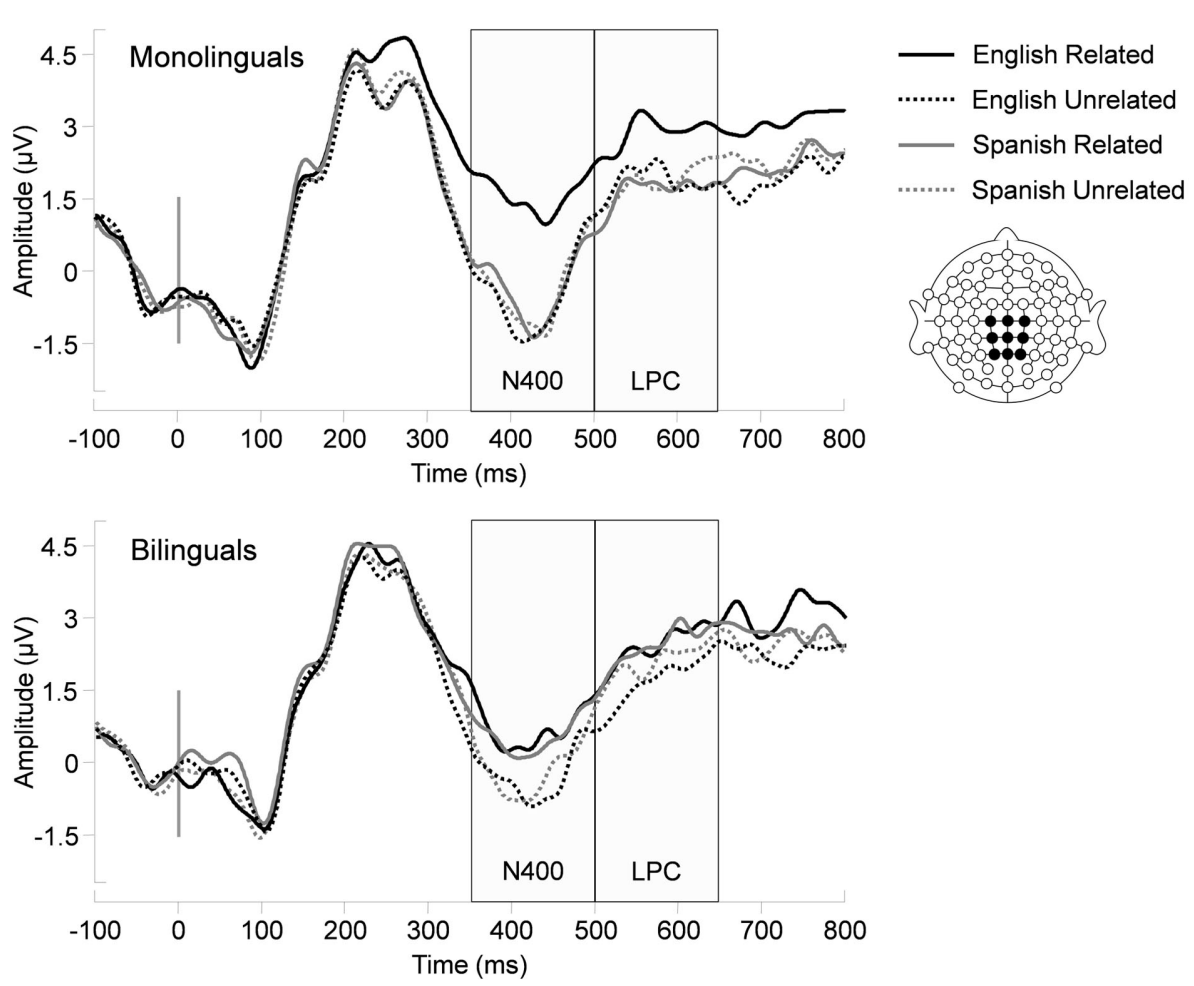

FIGURE 2 | ERPs measured over the centroparietal electrodes where N400 and LPC were maximal (a liner derivation of C1, Cz, C2, CP1, CPz, CP2, P1, $\mathrm{Pz}, \mathrm{P2}$ ) as a function of relatedness, homograph language, and language group. 
bilinguals showed that the mean amplitude of the related condition was less negative than that of the unrelated condition for both the English homograph meaning $[F(1,13)=7.15, p<0.05]$ and the Spanish homograph meaning $[F(1,13)=12.65, p<0.01]$.

\section{LPC (500-650 ms)}

The LPC was maximal over the centroparietal region. The main effect of relatedness was significant $[F(1,26)=11.07, p<0.01]$. The main effects of homograph language status and language group did not emerge $(F s<1)$. The interaction between relation and homograph language status was significant $[F(1,26)=5.56$, $p<0.05]$. Specifically, the mean amplitude was more positive in the related than unrelated condition in English $[F(1,27)=11.96$, $p<0.01]$. However, there was no difference between the related and unrelated conditions in Spanish $(F<1)$. The interactions between homograph language status and language group and between relation and language group were not significant $[F(1$, $26)=3.32, p=0.08 ; F<1$, respectively]. The three-way interaction of relatedness, homograph language status, and language group was not reliable $[F(1,26)=1.36, p>0.10]$.

\section{DISCUSSION}

The goal of the present study was to examine the time window in which the non-target language is accessed in late Spanish-English bilinguals reading English. The time course of the activation of homograph meanings in the non-target language was tracked using ERPs. We found that monolinguals displayed semantic priming only when primes were related to the English meaning of homograph targets. This semantic priming effect was observed in the N400 time window (350-500 ms) but also affected ERP amplitudes in the LPC time window (500-650 ms). In contrast, Spanish-English bilinguals showed semantic priming effects in the N400 time window (350-500 ms) when primes were related either to the English or the Spanish meaning of homograph targets. However, the LPC effect was found for stimulus pairs related on the basis of the English meaning of homographs only. These results suggest that both languages are activated in the classical time frame of semantic activation indexed by N400 modulations, but that semantic activation in the non-target language failed to be explicitly processed by bilingual participants.

The time course of activation of non-target homograph meaning in the present study is compatible with a previous ERP studies on processing of interlingual homographs out of context (Kerkhofs et al., 2006; Paulmann et al., 2006). In the study by Kerkhofs et al. (2006), the frequency effect in the non-target language, which was an index of non-target homograph meaning activation, was observed from 400 to $550 \mathrm{~ms}$ but was not found from 550 to $650 \mathrm{~ms}$. However, the present result contrasts with previous research on the processing of interlingual homographs in sentence context (Elston-Güttler et al., 2005). In the study by Elston-Güttler et al. (2005), German-English bilinguals activated the non-target meaning of homographs from 150 to $250 \mathrm{~ms}$ and from 300 to $500 \mathrm{~ms}$ only when their L1 German was activated through viewing a film in German prior to the experiment and only for the first half of the experiment. This result suggests that a sentence context can suppress non-target language activation before the stage of post-lexical processing.
The absence of explicit processing in the case of word pairs related via the non-target L1 is compatible with the inhibitory control (IC) model proposed by Green (1998). Indeed, if inhibition occurs, it is likely to intervene after automatic aspects of lexicosemantic processing. According to the IC model, both L1 and L2 lexico-semantic representations are activated and the selection of a target representation is dependent on the language which is more active at a given time. A task schema is hypothesized to be responsible for controlling the level of activation of lexico-semantic representations in the non-target language. When bilinguals intend to perform a task in one language, the task schema inhibits the activation of lexico-semantic representations in the non-target language. In the present study, Spanish-English bilinguals activated lexico-semantic representations with English and Spanish language tags while reading a series of pairs of English words, which was reflected in the N400 time window $(350-500 \mathrm{~ms})^{1}$. Although half of the trials included interlingual homographs in English and Spanish, the instructions were given exclusively in English, the experiment was introduced as consisting of English words, and precaution was taken not to mention the inclusion of interlingual homographs. Therefore, participants did not need to be aware of the presence of word targets related to prime via Spanish, and indeed they were not given the lack of an LPC variation in that condition.

Similarly, the bilingual interactive activation (BIA) + model (Dijkstra and van Heuven, 2002) is compatible with the absence of a modulation in the LPC range for interlingual homographs related via the non-target language $\mathrm{L} 1$. The BIA+ model assumes that the word identification system can be influenced by the linguistic context, but not by the non-linguistic context (e.g., task instruction, task demands, etc.), and that the influence of non-linguistic context on word recognition is post-lexical. In the present study, semantic priming effects were found for both meanings of interlingual homographs in the target and non-target languages in the N400 time window, which is supposed to reflect lexico-semantic processing. However, the semantic priming effect in the non-target language did not result in an LPC modulation, which is likely to reflect post-lexical re-evaluation processes associated with explicit access.

One concern about the design of the present study was the repetition of stimuli. As described in the Section "Materials and Methods," we used the same set of targets for all the experimental conditions in order to minimize the possibility that observed differences in ERPs across conditions would be due to differences in terms of stimulus physical features or lexical properties rather than to the relationship between prime and target. Four repetitions were involved in this design. To assess the effect of repetitions, we reanalyzed the bilingual data by including experimental block as an additional within-participants variable. A 2 (relatedness: related and unrelated) $\times 2$ (homograph language status: Spanish and English meaning) $\times 2$ (block: first half and second half) $\times 9$ (electrode site: $\mathrm{C} 1, \mathrm{C} 2, \mathrm{Cz}, \mathrm{CP} 1, \mathrm{CP} 2, \mathrm{CPz}, \mathrm{P} 1$, $\mathrm{P} 2$, and $\mathrm{Pz}$ ) ANOVA showed that the variable "block" did not

\footnotetext{
${ }^{1}$ We note that there was a marginal three-way interaction on $\mathrm{N} 2$ mean amplitudes as well, suggesting the lexical-semantic integration may have started slightly earlier in English monolinguals than Spanish-English bilinguals.
} 
interact with any other variable (all $p s>0.10$ ). This result suggests that the observed pattern of effects was not affected by repetitions.

In conclusion, the present ERP study suggests that bilinguals activate semantic representations of interlingual homographs in the non-target language as well as in the target language initially but process these representations at an explicit level only for meaning in the target language. In future research, it will be critical to investigate the role of L2 proficiency, the nature of the target language (e.g., L1 rather than L2), and the linguistic and non-linguistic contextual parameters in the modulation of

\section{REFERENCES}

Baayen, R. H., Piepenbrock, R., and Gulikers, L. (1995). The CELEX Lexical Database [CD-ROM]. Philadelphia, PA: University of Pennsylvania.

Beauvillain, C., and Grainger, J. (1987). Accessing interlexical homographs: some limitations of a languageselective access. J. Mem. Lang. 26, 658-672.

De Bruijn, E., Dijkstra, A., Chwilla, D. J., and Schriefers, H. J. (2001). Language context effects on interlingual homograph recognition: evidence from event-related potentials and response times in semantic priming. Biling. Lang. Cogn. 4, 155-168.

Dijkstra, A., Grainger, J., and van Heuven, W. J. B. (1999). Recognition of cognates and interlingual homographs: the neglected role of phonology. J. Mem. Lang. 41, 496-518.

Dijkstra, A., Van Jaarsveld, H., and Ten Brinke, S. (1998). Interlingual homograph recognition: effects of task demands and language intermixing. Biling. Lang. Cogn. 1, 51-66.

Dijkstra, T., and van Heuven, W. J. B. (2002). The architecture of the bilingual word recognition system: from identification to decision. Biling. Lang. Cogn. 5, 175-197.

Elston-Güttler, K. E. (2000). An Inquiry into Cross-Language LexicalConceptual Relationships and Their Effect on L2 Lexical Processing. Unpublished doctoral dissertation, University of Cambridge, Cambridge.

Elston-Güttler, K. E., Gunter, T. C., and Kotz, S. A. (2005). Zooming into L2: global language context and adjustment affect processing of interlingual homographs in sentences. Brain Res. Cogn. Brain Res. 25, 57-70.

Green, D. W. (1998). Mental control of the bilingual lexico-semantic system. Biling. Lang. Cogn. 1, 67-81.

Greenhouse, S. W., and Geisser, S. (1959). On methods in the analysis of profile data. Psychometrica 24, 95-112.

Hoshino, N., Midgley, K. J., Holcomb, P. J., and Grainger, J. (2010). An ERP investigation of masked cross-script translation priming. Brain Res. 1344, 159-172.

Hoshino, N., and Thierry, G. (2011). Language selection in bilingual word production: electrophysiological evidence for cross-language competition. Brain Res. 1371, 100-109.

Jared, D., and Kroll, J. F. (2001). Do bilinguals activate phonological replanguages when naming words? J. Mem. Lang. 44, 2-31.

Kerkhofs, R., Dijkstra, A., Chwilla, D., and De Bruijn, E. (2006). Testing a model for bilingual semantic priming with interlingual homographs: RT and ERP effects. Brain Res. 1068, 170-183.

Kuipers, J. R., and Thierry, G. (2010). Event-related brain potentials reveal the time-course of language change detection in early bilinguals. Neuroimage 50, 1633-1638.

Kutas, M., and Hillyard, S. A. (1980). Reading senseless sentences: brain potentials reflect semantic incongruity. Science 207, 203-205.

Lemhöfer, K., and Dijkstra, T. (2004). Recognizing cognates and interlexical homographs: effects of code similarity in language specific and generalized lexical decision. Mem. Cognit. 32, 533-550.

Luck, S. J. (2005). An Introduction to the Event-Related Potential Technique. Cambridge, MA: MIT Press.

Macizo, P., Bajo, T., and Martín, M. C. (2010). Inhibitory processes in bilingual language comprehension: evidence from Spanish-English interlexical homographs. J. Mem. Lang. 63, 232-244.

Martin, C. D., Costa, A., Dering, B., Hoshino, N., Wu, Y. J., and Thierry, G. (2012). Effects of speed of word processing on semantic access: the resentations in one or both of their

cross-languages activation at lexical and post-lexical processing stages (cf., Wu and Thierry, 2010). If the target language were the L1, the activation of the non-target language might not be present because of the relatively weaker representations in L2. Resolving these issues will provide implications for models of bilingual language processing.

\section{ACKNOWLEDGMENTS}

This research was supported by the Economic and Social Research Council U.K. (RES-E024556-1). We thank Jan-Rouke Kuipers and Clara Martin for technical assistance.

case of bilingualism. Brain Lang. 120, 61-65.

Martin, C. D., Dering, B., Thomas, E. M., and Thierry, G. (2009). Brain potentials reveal semantic priming in both the 'active' and the 'non-attended' language of early bilinguals. Neuroimage 47, 326-333.

Martin, C. D., Thierry, G., and Démonet, J. F. (2010). ERP characterization of sustained attention effects in visual lexical categorization. PLoS ONE 5, e9892. doi:10.1371/journal.pone.0009892

Martín, M. C., Macizo, P., and Bajo, T. (2010). Time course of inhibitory processes in bilingual language processing. Br. J. Psychol. 101, 679-693.

Midgley, K. J., Holcomb, P. J., and Grainger, J. (2009). Masked repetition and translation priming in second language learners: a window on the time-course of form and meaning activation using ERPs. Psychophysiology 46, 551-565.

Paulmann, S., Elston-Güttler, K. E. Gunter, T. C., and Kotz, S. A. (2006). Is bilingual lexical access influenced by language context? Neuroreport 17 , 727-731.

Picton, T. W., Bentin, S., Berg, P. Donchin, E., Hillyard, S. A., Johnson, R. Jr., Miller, G. A., Ritter, W., Ruchkin, D. S., Rugg, M. D., and Taylor, M. J.(2000). Guidelines for using human eventrelated potentials to study cognition: recording standards and publication criteria. Psychophysiology 37, 127-152.

Thierry, G., Athanasopoulos, A., Wiggett, A., Dering, B., and Kuipers, J. R. (2009). Unconscious effects of language-specific terminology on preattentive color perception. Proc. Natl. Acad. Sci. U.S.A. 106, 4567-4570.

Thierry, G., Cardebat, D., and Démonet, J.-F. (2003). Electrophysiological comparison of grammatical processing and semantic processing of single spoken nouns. Brain Res. Cogn. Brain Res. 17, 535-547.
Thierry, G., Doyon, B., and Démonet, J. F. (1998). ERP mapping in phonological and lexical semantic monitoring tasks: a study complementing previous PET results. Neuroimage 8, 391-408.

Thierry, G., and Wu, Y. J. (2007). Brain potentials reveal unconscious translation during foreign language comprehension. Proc Natl. Acad. Sci. U.S.A. 104, 12530-12535.

Tokowicz, N., Michael, E., and Kroll, J. F. (2004). The roles of study abroad experience and working memory capacity in the types of errors made during translation. Biling. Lang. Cogn. 7, 255-272.

Wu, Y. J., and Thierry, G. (2010). Investigating bilingual processing: the neglected role of language processing contexts. Front. Psychol. 1:178. doi:10.3389/fpsyg.2010.00178

Conflict of Interest Statement: The authors declare that the research was conducted in the absence of any commercial or financial relationships that could be construed as a potential conflict of interest.

Received: 08 May 2011; accepted: 09 January 2012; published online: 02 February 2012.

Citation: Hoshino $N$ and Thierry $G$ (2012) Do Spanish-English bilinguals have their fingers in two pies - or is it their toes? An electrophysiological investigation of semantic access in bilinguals. Front. Psychology 3:9. doi: 10.3389/fpsyg.2012.00009

This article was submitted to Frontiers in Cognition, a specialty of Frontiers in Psychology.

Copyright (c) 2012 Hoshino and Thierry. This is an open-access article distributed under the terms of the Creative Commons Attribution Non Commercial License, which permits non-commercial use, distribution, and reproduction in other forums, provided the original authors and source are credited. 